\title{
BMJ Open Hospitalisation at the end of life among cancer and non-cancer patients in Denmark: a nationwide register-based cohort study
}

\author{
Anne Høy Seemann Vestergaard (D , , ${ }^{1}$ Mette Asbjoern Neergaard, ${ }^{2}$ \\ Christian Fynbo Christiansen, ${ }^{1}$ Henrik Nielsen, ${ }^{1}$ Thomas Lyngaa, ${ }^{1}$ \\ Kristina Grønborg Laut, ${ }^{1}$ Søren Paaske Johnsen ${ }^{3}$
}

To cite: Vestergaard AHS, Neergaard MA, Christiansen CF, et al. Hospitalisation at the end of life among cancer and noncancer patients in Denmark: a nationwide register-based cohort study. BMJ Open 2020;10:e033493. doi:10.1136/ bmjopen-2019-033493

- Prepublication history and additional material for this paper are available online. To view these files, please visit the journal online (http://dx.doi. org/10.1136/bmjopen-2019033493).

Received 07 August 2019 Revised 06 February 2020 Accepted 18 May 2020

\section{Check for updates}

(C) Author(s) (or their employer(s)) 2020. Re-use permitted under CC BY-NC. No commercial re-use. See rights and permissions. Published by BMJ.

${ }^{1}$ Department of Clinical Epidemiology, Aarhus University Hospital, Aarhus, Denmark

${ }^{2}$ The Palliative Care Team, Department of Oncology, Aarhus University Hospital, Aarhus, Denmark

${ }^{3}$ Danish Center for Clinical Health Services Research, Aalborg University, Aalborg, Denmark

Correspondence to Professor Søren Paaske Johnsen; soeren.johnsen@rn.dk

\section{ABSTRACT}

Objectives End-of-life hospitalisations may not be associated with improved quality of life. Studies indicate differences in end-of-life care for cancer and non-cancer patients; however, data on hospital utilisation are sparse. This study aimed to compare end-of-life hospitalisation and place of death among patients dying from cancer, heart failure or chronic obstructive pulmonary disease (COPD).

Design A nationwide register-based cohort study.

Setting Data on all in-hospital admissions obtained from nationwide Danish medical registries.

Participants All decedents dying from cancer, heart failure or COPD disease in Denmark between 2006 and 2015.

Outcome measures Data on all in-hospital admissions within 6 months and 30 days before death as well as place of death. Comparisons were made according to cause of death while adjusting for age, sex, comorbidity, partner status and residential region.

Results Among 154235 decedents, the median total bed days in hospital within 6 months before death was 19 days for cancer patients, 10 days for patients with heart failure and 11 days for patients with COPD. Within 30 days before death, this was 9 days for cancer patients, and 6 days for patients with heart failure and COPD. Compared with cancer patients, the adjusted relative bed day use was $0.65(95 \% \mathrm{Cl}, 0.63$ to 0.68$)$ for heart failure patients and $0.68(95 \% \mathrm{Cl}, 0.66$ to 0.69$)$ for patients with COPD within 6 months before death. Correspondingly, this was 0.65 (95\% Cl, 0.63 to 0.68$)$ and $0.70(95 \% \mathrm{Cl}, 0.68$ to 0.71$)$ within 30 days before death.

Patients had almost the same risk of dying in hospital independently of death cause (46.2\% to $56.0 \%)$.

Conclusion Patients with cancer, heart failure and COPD all spent considerable part of their end of life in hospital. Hospital use was highest among cancer patients; however, absolute differences were small.

\section{INTRODUCTION}

Most patients with chronic diseases prefer to remain at home as much as possible towards the end of life, and a high level of hospital care in the last months of life may, therefore,
Strengths and limitations of this study

- The main strengths include the nationwide population-based design in the setting of a uniformly organised healthcare system where accurate linkage between national medical registries is possible.

- The study was based on prospectively collected data from registries, which are considered to have a high validity.

- Analyses were based on the underlying cause of death of well-defined chronic diseases in order to avoid introducing misclassification, since it remains difficult to determine and differentiate between underlying and immediate cause of death.

- Register-based data give some limitations to the study as these cannot provide detailed information on patients' disease status, palliative needs and preferences in order to differentiate whether noncancer and cancer patients are hospitalised for comparable reasons.

not be associated with improved quality of life. ${ }^{1-7}$ Nevertheless, terminally ill patients may spend considerable time in hospitals and often die there. $^{28}$

Prior research indicate that end-of-life care to patients with non-cancer diagnoses may be sub-optimal compared with that of patients with cancer diagnoses, and that healthcare professionals are often better educated to identify the terminal phase and manage endof-life care among cancer patients. ${ }^{9-11}$ Difficulties in predicting illness trajectories for non-cancer patients approaching the end of life are likely to explain some of the difference in access to palliative care services between cancer and non-cancer patients. ${ }^{12-19}$ Thus, even though incurably ill non-cancer patients experience similar physical and psychosocial needs as cancer patients, they may receive fewer palliative care services and thereby more often experience hospitalisations in 
the end of life. ${ }^{90-31}$ However, there is a paucity of large scale population-based studies comparing healthcare utilisation among terminally ill non-cancer and cancer patients and it is consequently difficult for healthcare professionals, administrators and health policy makers to address potential inequalities. More insight is warranted on care needs among end-of-life patients across different disease conditions in order to understand current illness trajectories and to ensure that healthcare systems are responsive and appropriately organised to meet palliative care needs.

We therefore compared hospitalisation patterns within the last 6 months and 30 days before death as well as place of death for all Danes who died of cancer with those who died of heart failure or chronic obstructive pulmonary disease (COPD). We also examined the trends according to calendar years of death in order to identify any temporal changes.

\section{METHODS}

\section{Study design and setting}

We conducted a nationwide follow-up study among all adult decedents in Denmark who died from cancer, heart failure or COPD from 1 January 2006 to 31 December 2015. The study was based on individual-level linkage of national medical registries using the 10-digit unique personal civil registration number assigned to all Danish residents. ${ }^{32} 33$

The healthcare system in Denmark is tax-supported and provided to all residents, who thereby have equal access to healthcare, including access to public hospitals, hospices, general practitioners and specialists in palliative care. Private hospitals play a minor role in Denmark and only for elective surgical and diagnostic procedures. Only public hospitals are involved in acute medical and palliative care.

In accordance with Danish law, non-interventional studies in Denmark do not require approval from ethics committees. The current study was approved by the Danish Data Protection Agency on 4 July 2014 (Central Denmark Region record number: 1-16-02-407-14).

\section{Decedents}

We used the Danish Register of Causes of Death to identify all decedents at the age of 18 years or older, who had been residents in Denmark for at least 6 months before death and registered with cancer (International Classification of Diseases, Tenth Revision (ICD-10) codes: DC00-14, DC15-26, DC30-39, DC40-41, DC43-44, DC50, DC51-58, DC60-63, DC64-68, DC69-72, DC73-75, DC76-80, DC8196), heart failure (ICD-10 codes: I11.9, I13.0, I13.2, I42.0, I42.6, I42.7, I42.9, I50.0, I50.1, I50.9) or COPD (ICD-10 codes: J41-44, J47) as the underlying cause of death.

Independence between the three patient populations was ensured by excluding patients, who died of one of the three conditions while also having a history of one or both of the other conditions according to information from the Danish National Patient Registry (please see below for information on this registry). Hence, a patient with cancer as the underlying cause of death was excluded if he/she had one or more previous hospital contacts for COPD and/or heart failure.

The Danish Register of Causes of Death is a nationwide registry with data collection since 1970 with a completeness of approximately $97 \% .{ }^{34}$ Data are obtained from death certificates filled for every decedent and include civil registration number, date of death, manner of death and cause of death, both immediate and underlying, reported as a chain of one to four conditions that led to death. Causes of death are coded according to the Danish version of ICD. ${ }^{35}$

\section{Hospital admissions}

We identified all hospital admissions, including public and private hospitals, within 6 months before death on all included patients using the Danish National Patient Registry. The Danish National Patient Registry was established in 1977, and since then it has been mandatory for all Danish hospitals to register information on hospital admissions, including dates of all admissions and discharges, patients' discharge diagnoses, surgical procedures and patients' residence. ${ }^{36}$

Using the Danish National Patient Registry, we retrieved the following data on the study population: (1) the total number of bed days, (2) the total number bed days initiated by acute and elective admissions, (3) the total number of admissions and the corresponding number of days per admission and (4) the number and proportion of patients hospitalised on date of death.

In addition, we retrieved data on age at death, sex, comorbidity (assessed using the Charlson Comorbidity Index ${ }^{3738}$ and residential region using the Danish National Patient Registry, and data regarding partner status using The Danish Civil Registration System for all patients. ${ }^{33}$ We computed the Charlson Comorbitdity Index based on the entire hospitalisation history of each patient in the 10 years leading up to death, including both admissions with overnight stay and outpatient visits. The weights of 19 selected conditions were summed to a comorbidity score excluding the cause of death. ${ }^{37} 38$

\section{Statistical methods}

Median total bed days within 6 months and 30 days before death and the corresponding percentages of time spent in hospital were estimated for the three patient populations. In the same way, we estimated the median total bed days within 6 months and 30 days before death after acute and elective hospital admissions.

For each patient population, we computed the median number of hospital admissions and median days per hospital admission within 6 months and 30 days before death. We also computed the proportion of patients dying in hospital.

Finally, we estimated the relative total bed days, relative bed days after acute admission and elective admission, 
relative number of hospital admissions, relative length per admission and the relative risk of dying during hospital admission for patients who died of heart failure or COPD compared with patients who died of cancer. The relative estimates were adjusted for age, sex, comorbidity, partner status and residential region using linear regression analysis transformed by natural logarithm. Similarly, the adjusted relative risk of dying during hospital admission were estimated using multivariable binomial regression.

The statistical analyses were performed using Stata 14.2 (StataCorp. 2015. Stata Statistical Software: Release 14. College Station, TX: StataCorp LP) on a secure remote server of Statistics Denmark.

\section{Patient and public involvement}

There were no patients or members of the public involved in the design, conduct, analyses or reporting of our research.

\section{RESULTS}

We identified 154235 patients who died of cancer $(n=123212)$, heart failure $(n=9758)$ or COPD $(n=21265)$ between 2006 and 2015. Among these decedents, 90.7\% were admitted to hospital at least once within the last 6 months of life (398983 admissions) (table 1).

\section{Bed day use}

Among the decedents included in the study, the median total bed days in hospital within 6 months before death was 19 days for cancer patients, 10 days for heart failure patients and 11 days for COPD patients (table 2).

The median total bed days within the last 30 days before death was 9 days for cancer patients and 6 days for heart failure and COPD patients (table 2).

The median total bed days within 6 months before death decreased from 2006 to 2015 for cancer patients, whereas it remained unchanged for heart failure and COPD patients (figure 1). The number of total bed days within 30 days as well as the number of hospitals admissions and length of stay per admission within 6 months and 30 days before death remained stable for all patient populations during the study period (data not shown).

The adjusted relative bed days within 6 months before death was 0.65 (95\% CI, 0.63 to 0.67 ) for heart failure

Table 1 Characteristics of patients who died of cancer, heart failure or COPD in Denmark between 2006 and 2015

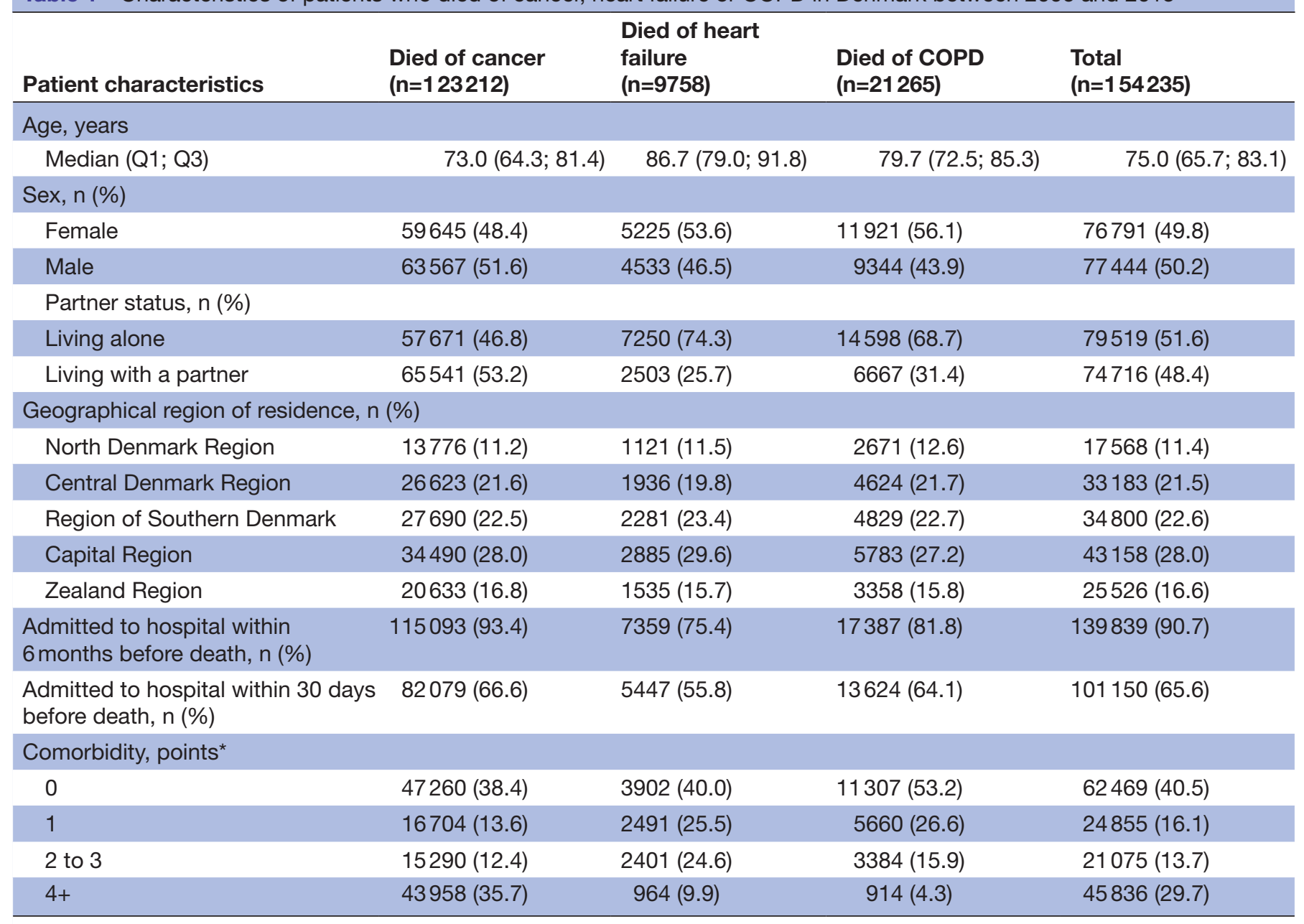

${ }^{*}$ Calculated according to Charlson Comorbidity Index, excluding underlying cause of death.

COPD, chronic obstructive pulmonary disease. 
Table 2 Hospitalisation use according to underlying disease: total bed days in hospital, proportion of bed days, number of hospital admissions, length per admission and proportion of patients dying in hospital

\begin{tabular}{|c|c|c|c|c|}
\hline Hospital admissions & Died of cancer & Died of heart failure & Died of COPD & Total \\
\hline \multicolumn{5}{|l|}{ Total bed day use, days, median (Q1; Q3) } \\
\hline 6 months before death & $19(9 ; 34)$ & $10(4 ; 23)$ & $11(5 ; 23)$ & $17(8 ; 32)$ \\
\hline 30 days before death & $9(4 ; 15)$ & $6(2 ; 11)$ & $6(2 ; 12)$ & $8(3 ; 15)$ \\
\hline \multicolumn{5}{|l|}{ Proportion of bed days, \% } \\
\hline 6 months before death & 10.4 & 5.5 & 6 & 9.3 \\
\hline 30 days before death & 30 & 20 & 20 & 26.7 \\
\hline \multicolumn{5}{|l|}{$\begin{array}{l}\text { Number of hospital admissions, } \\
\mathrm{n}(\mathrm{Q} 1 ; \mathrm{Q} 3)\end{array}$} \\
\hline 6 months before death & $2(1 ; 4)$ & $1(1 ; 2)$ & $2(1 ; 3)$ & $2(1 ; 4)$ \\
\hline 30 days before death & $1(1 ; 2)$ & $1(1 ; 1)$ & $1(1 ; 1)$ & $1(1 ; 2)$ \\
\hline \multicolumn{5}{|c|}{ Length of stay per hospital admission, days, median (Q1; Q3) } \\
\hline 6 months before death & $4(1 ; 10)$ & $6(2 ; 11)$ & $5(2 ; 10)$ & $4(1 ; 10)$ \\
\hline 30 days before death & $5(2 ; 11)$ & $5(2 ; 10)$ & $5(2 ; 10)$ & $5(2 ; 11)$ \\
\hline Proportion of patients dying in hospital, \% & 56 & 46.2 & 55.5 & 55.3 \\
\hline
\end{tabular}

COPD, chronic obstructive pulmonary disease.

patients and 0.68 (95\% CI, 0.66 to 0.69$)$ for COPD patients when compared with cancer patients (table 3 ). Unadjusted results are available in online supplementary table 1 . The adjusted relative bed days were relatively unchanged when restricting the analyses to the last 30 days before death (table 3 ).

Within 6 months before death, acute admissions accounted for $76.0 \%$ of all hospital admissions of cancer patients, whereas this was $93.5 \%$ for heart failure patients and $96.0 \%$ for COPD patients. Correspondingly, within 30 days before death, this was $84.3 \%$ for cancer patients, 96.3\% for heart failure patients and $97.9 \%$ for COPD patients.

Among patients acutely admitted to hospital within 6 months before death, the median total bed days within this period was 16 days for cancer patients, 11 days for heart failure patients and 12 days for COPD patients. Within the

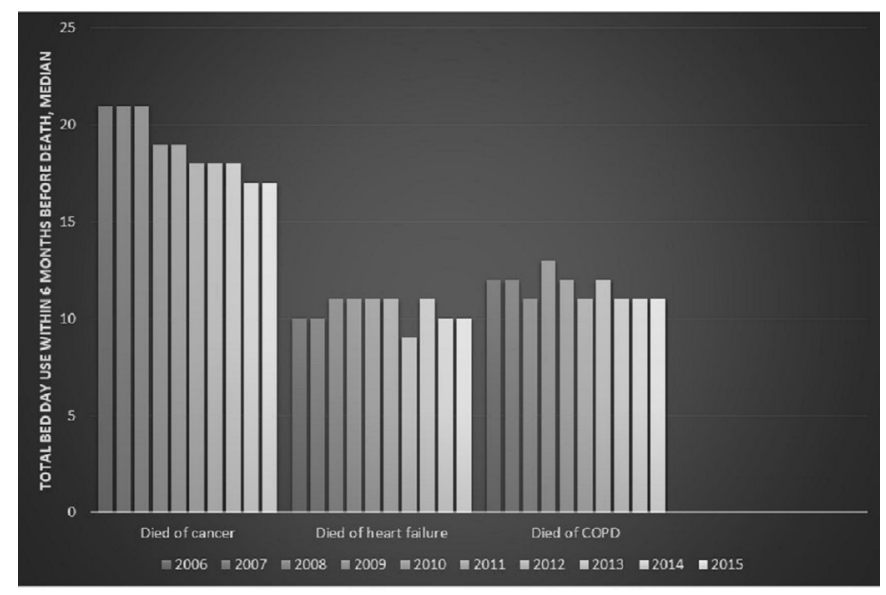

Figure 1 Total bed day use within 6 months before death according to cause of death and calendar year. last 30 days before death, the median total bed days initiated by acute admission was 8 days for cancer patients and 6 days for both heart failure and COPD patients.

Correspondingly, the median total bed days initiated by elective admission within 6 months before death was 5 days for cancer patients, 4 days for heart failure patients and 3 days for COPD patients, and within 30 days before death, this was 6 days for cancer patients and 4 days for both heart failure and COPD patients.

The adjusted relative bed days initiated by acute and elective admission showed less difference between the three patient populations as for the total number of days in hospital, both within 6 months and 30 days before death.

\section{Number of hospital admissions and length per admission}

Patients who died from cancer or COPD had a median of two hospital admissions within 6 months before death, whereas patients who died of heart failure had a median of one hospital admission within 6 months before death (table 2). Within the last 30 days leading up to death, all patient populations had a median of one hospital admission (table 2). The number of admissions did not vary systematically when stratified by calendar years of death (online supplementary table 2 ).

We observed variation in the number of admissions within 6 months before death in the adjusted estimates, comparing heart failure patients $(0.84$ (95\% CI, 0.83 to $0.85)$ ) and COPD patients $(0.85$ (95\% CI, 0.84 to 0.86$)$ ) with cancer patients (table 3). Less variation in the number of admissions was identified when restricting analyses to patients admitted to hospital within 30 days before death (heart failure patients: 0.95 (95\% CI, 0.94 to 0.96), COPD patients: 0.95 (95\% CI, 0.95 to 0.96 )). 
Table 3 Adjusted relative use of hospital for patients who died of heart failure or COPD when compared with patients with cancer

\begin{tabular}{|c|c|c|c|}
\hline Hospital admissions & Died of cancer & Died of heart failure* & Died of COPD* \\
\hline \multicolumn{4}{|l|}{ Relative total bed day use $(95 \% \mathrm{Cl})$} \\
\hline 6 months before death & 1.0 (reference) & $0.65(0.63$ to 0.67$)$ & $0.68(0.66$ to 0.69$)$ \\
\hline \multicolumn{4}{|l|}{ Relative number of hospital admissions $(95 \% \mathrm{Cl})$} \\
\hline 6 months before death & 1 & $0.84(0.83$ to 0.85$)$ & $0.85(0.84$ to 0.86$)$ \\
\hline \multicolumn{4}{|l|}{ Relative length of stay per hospital admission $(95 \% \mathrm{Cl})$} \\
\hline 6 months before death & 1 & 1.07 (1.04 to 1.10$)$ & $1.15(1.13$ to 1.17$)$ \\
\hline 30 days before death & 1 & $0.75(0.72$ to 0.78$)$ & $0.82(0.80$ to 0.84$)$ \\
\hline Prevalence proportion ratio of in-hospital death $(95 \% \mathrm{Cl})$ & 1 & $1.03(1.00$ to 1.06$)$ & $0.95(0.93$ to 0.97$)$ \\
\hline
\end{tabular}

${ }^{*}$ Adjusted for age, sex, comorbidity, partner status and residential region. COPD, chronic obstructive pulmonary disease.

Patients' median length of stay per hospital admission within the last 6 months of life was 4 days for cancer patients, 6 days for heart failure patients and 5 days for COPD patients (table 2). Median length of stay within the last 30 days of life was 5 days for all patient populations. Limited differences between cancer and non-cancer patients were observed when adjusting for the covariates. For hospital admissions within 6 months before death, the adjusted relative median length per hospital admission was 1.07 (95\% CI, 1.04 to 1.10) for heart failure patients and 1.15 (95\% CI, 1.13 to 1.17) for COPD patients when compared with cancer patients (table 3). Correspondingly, for hospital admissions within 30 days before death, the adjusted relative median length per hospital admission was 0.75 (95\% CI, 0.72 to 0.78$)$ for heart failure patients and 0.82 (95\% CI, 0.80 to 0.84 ) for COPD patients when compared with cancer patients (table 3 ).

\section{Place of death}

The proportion of patients dying in hospital was $56.0 \%$ of cancer patients, $46.2 \%$ of heart failure patients and $55.5 \%$ of COPD patients (table 2).

The adjusted relative risk of dying in hospital was 1.03 (95\% CI, 1.00 to 1.06) for heart failure patients and 0.95 (95\% CI, 0.93 to 0.97 ) for COPD patients when compared with cancer patients (table 3 ).

\section{DISCUSSION}

We found that hospitalisation near the end of life was common irrespective of the underlying disease, although the total number of bed days in hospital within 6 months before death has been reduced for all patients between 2006 and 2015. Compared with patients dying of cancer, non-cancer patients had shorter total bed days but comparable length per hospital admission and number of hospital admissions within both the last 6 months and 30 days before death. Still, there were no major differences in the risk of dying in hospital for cancer versus noncancer patients.

The main strengths of our study include the nationwide population-based design in the setting of a uniformly organised healthcare system where accurate linkage between national medical registries is possible. The study was based on data from registries, which are considered to have a high validity. ${ }^{36}$

However, the limitations should also be taken into account. The method that we used to examine hospitalisations for patients at the end of life using a sample of decedents only, has been criticised, as it artificially removes the uncertainty of prognostication in patients at the end of life ${ }^{39}$ Yet, it is a clinical challenge to determine when patients enter the terminal phase of life, wherefore a traditional follow-up study would be difficult. Our analyses were based on the underlying cause of death of welldefined chronic diseases in order to avoid introducing misclassification, since it remains difficult to determine and differentiate between underlying and immediate cause of death. Validation of the Danish Register of Causes of Death is sparse and only performed for some diseases, leaving some uncertainty about classification of the causes of death; however, selection bias is unlikely. ${ }^{40}$ In the Danish National Patient Registry, only few admissions and discharges are not registered, which indicates low risk of information bias concerning patients' end-oflife hospitalisations. ${ }^{36}$

Register-based data give some limitations to the study as these cannot provide detailed information on patients' disease status, palliative needs and preferences in order to differentiate whether non-cancer and cancer patients are hospitalised for comparable reasons. There may also be residual confounding and confounding from unmeasured factors, since information on lifestyle factors, socioeconomic status, severity of illness and other factors was not available in the current study. 
Previous studies examining end-of-life care for deceased cancer patients have shown that hospitalisations near the end of life are very frequent across countries and healthcare systems. ${ }^{41}$ However, existing data directly comparing end-of-life care patterns for cancer and non-cancer patients are sparse, and the studies are small with a few exceptions.

A US study comparing end-of-life care patterns within 6 months before death among COPD and lung cancer patients ( $\mathrm{n}=1949)$ also found that COPD and lung cancer patients had a similar risk of dying in hospital. ${ }^{30}$ However, unlike our study, they found, that COPD patients had fewer hospital admissions compared with lung cancer patients, and that the total hospital bed days was similar for COPD and lung cancer patients. Since the sample population in the US study was smaller than in the current study and predominantly included elderly white men, this may explain some of the variation between the findings in the two studies.

Teno et al examined changes in site of death, place of care and healthcare transitions between 2000, 2005 and 2009 among a 20\% sample of Medicare beneficiaries, aged 66 years and older. ${ }^{42}$ Improvements in care were observed over time for all patients; however, COPD patients were consistently more likely to die in acute care settings and received less hospice care compared with cancer patients. In contrast, no major difference in bed day use within 90 days before death was observed.

Wachterman et al conducted a cross-sectional study in all 146 inpatient facilities within the Veteran Affairs health system. ${ }^{43}$ The study included 57753 decedents, all of whom died in inpatients facilities. Patients with COPD and/or heart failure had a lower chance of receiving palliative care consultations and a higher risk of dying in the intensive care unit compared with patients with cancer. Moreover, the chance of receiving excellent quality of end-of-life care as reported by the decedents' families was also lower for patients with COPD and/or heart failure.

Finally, Lastrucci et al recently reported a registry study from the Tuscany region in Italy where they compared indicators for quality of end-of-life care between patients with COPD or heart failure and cancer. ${ }^{44}$ For all indicators, patients dying from COPD or heart failure came out worse, including a higher risk of dying in an acute care hospital and being hospitalised or admitted to the emergency department and a lower chance of using hospice services in the last month of life compared with cancer patients.

Studies have suggested that variation in end-of-life care among patients with different underlying disease is caused by the perceived unpredictable illness trajectories of non-malignant chronic illnesses. ${ }^{12-19}$ Since early recognition of impending death is known to be crucial for optimal care for terminally ill patients, end-of-life care is challenging among non-cancer patients, whose illness trajectories tend to be less predictable compared with that of cancer patients. ${ }^{40}$ Therefore, we expected the current study to reveal that non-cancer patients spent more time in hospital compared with cancer patients, but this was not the case. One reason may be that improved cancer treatments are likely to have implications for the disease course, wherefore this may begin to resemble that of non-cancer patients.

Studies report that patients with non-cancer conditions have equivalent or even greater symptom burden, compared with those with cancer. ${ }^{17} 414546$ The slightly lower use of hospital among non-cancer patients found in the current study could therefore indicate that the symptom relief of non-cancer patients to a larger extent, as for cancer patients, were met in another setting (eg, by general practitioners). In fact, previous findings indicate that patients who receive home-based palliative care or palliative care from their general practitioner spend less time in hospital at the end of life. ${ }^{39} 47-53$ However, it may also indicate that the palliative needs of symptom relief among non-cancer patients are not acknowledged as such. In a recent study, we found, that patients dying from non-cancer conditions were twice as likely to be admitted to intensive care units at the end of life. ${ }^{54}$ This may indicate that non-cancer patients are treated aggressively and maybe unnecessarily towards the end of life, although the current study showed that their overall bed day use was somewhat lower compared with cancer patients. Still, non-cancer patients were more likely than cancer patients to be acutely admitted to hospital, and when looking only at acute and elective admissions, the bed day use of cancer and non-cancer patients was almost the same. This may suggest that non-cancer and cancer patients are not admitted to hospital for completely comparable reasons. Yet, further efforts are needed in order to disentangle the mechanisms leading to admissions for different patient populations and to explore whether these could have been avoided.

Our findings of decrease in hospital bed day use between 2006 and 2015 could be explained by the increasing number of outpatient treatments in the Danish healthcare system in general, replacing some hospital admissions. ${ }^{55}$ Nevertheless, some of the decrease may also be explained by increased levels of out-of-hospital palliative care in Denmark during the period, where the specialised palliative care approach has advanced substantially over the past decade along with an increased focus on palliative care in the rest of the healthcare system. ${ }^{56}$

The current study does not allow us to determine whether the observed high levels of end-of-life hospitalisation are appropriate for cancer and non-cancer patients, nor whether it reflects unmet palliative needs, lack of communication about end-of-life preferences, or difficulties recognising patients having terminal prognosis. Nevertheless, the high levels of hospitalisation use and death at hospital warrants consideration of whether palliative needs are appropriately accommodated. Furthermore, the findings question the common belief that inequality in palliative care exists among terminally ill patients with different underlying diagnosis. Still, more extensive information on end-of-life 
care patterns will be required in order to clarify these important issues.

\section{CONCLUSION}

Patients with cancer, heart failure and COPD, all spent a substantial part of their time at the end of life being hospitalised, and a high proportion of the patients continue to die in hospital settings. The use of hospitalisations was highest among cancer patients, although the absolute differences were small, and for all patient populations, it decreased between 2006 and 2015. Still, more insights in end-of-life care patterns are required in order to clarify the balance between patient needs and the care delivered by the healthcare system.

Contributors AHSV, MAN and SPJ initiated and designed the study. CFC, HN, TL and KGL performed further development. Acquisition of data was done by AHSV, HN and SPJ. AHSV performed the statistical analysis with assistance from HN and TL. AHSV drafted the manuscript which was critically reviewed by all authors. AHSV, MAN, CFC, HN, TL, KGL and SPJ all read and approved the final version of the manuscript.

Funding This works was supported by the Independent Research Fund Denmark, grant number: 4004-00609B; Fonden af 1870, grant number: 200652; C.C. Klestrup \& Hustru Henriette Klestrups Mindelegat, grant number: 10761; Fabrikant Einar Willumsens Mindelegat, grant number: 131217.

Competing interests None declared.

Patient and public involvement Patients and/or the public were not involved in the design, or conduct, or reporting, or dissemination plans of this research.

Patient consent for publication Not required.

Provenance and peer review Not commissioned; externally peer reviewed.

Data availability statement No data are available. Data are available as presented in the paper. According to Danish legislation, our approvals to use the Danish data sources for the current study do not allow us to distribute or make patient data directly available to other parties.

Open access This is an open access article distributed in accordance with the Creative Commons Attribution Non Commercial (CC BY-NC 4.0) license, which permits others to distribute, remix, adapt, build upon this work non-commercially, and license their derivative works on different terms, provided the original work is properly cited, appropriate credit is given, any changes made indicated, and the use is non-commercial. See: http://creativecommons.org/licenses/by-nc/4.0/.

ORCID iD

Anne Høy Seemann Vestergaard http://orcid.org/0000-0002-5140-1803

\section{REFERENCES}

1 Neergaard MA, Jensen AB, Sondergaard J, et al. Preference for place-of-death among terminally ill cancer patients in Denmark. Scand J Caring Sci 2011;25:627-36.

2 Brogaard T, Neergaard MA, Sokolowski I, et al. Congruence between preferred and actual place of care and death among Danish cancer patients. Palliat Med 2013;27:155-64.

3 Stajduhar KI, Allan DE, Cohen SR, et al. Preferences for location of death of seriously ill hospitalized patients: perspectives from Canadian patients and their family caregivers. Palliat Med 2008;22:85-8.

4 Townsend J, Frank AO, Fermont D, et al. Terminal cancer care and patients' preference for place of death: a prospective study. BMJ 1990;301:415-7.

5 Gomes B, Higginson IJ, Calanzani N, et al. Preferences for place of death if faced with advanced cancer: a population survey in England, Flanders, Germany, Italy, the Netherlands, Portugal and Spain. Ann Oncol 2012;23:2006-15.

6 Skorstengaard MH, Neergaard MA, Andreassen P, et al. Preferred place of care and death in terminally ill patients with lung and heart disease compared to cancer patients. J Palliat Med 2017;20:1217-24.

7 Zilberberg MD, Shorr AF. Economics at the end of life: hospital and ICU perspectives. Semin Respir Crit Care Med 2012;33:362-9.

8 Pocock LV, Ives A, Pring A, et al. Factors associated with hospital deaths in the oldest old: a cross-sectional study. Age Ageing 2016;45:372-6.

9 The Solid Facts. Palliative care.Tipolitografia Trabella SRL. Milan, Italy: The World Health Organization, 2004.

10 Couchoud C, Arnaud DB, Lobbedez T, et al. Access to and characteristics of palliative care-related hospitalization in the management of end-stage renal disease patients on renal replacement therapy in France. Nephrology 2017;22:598-608.

11 Poonja Z, Brisebois A, van Zanten SV, et al. Patients with cirrhosis and denied liver transplants rarely receive adequate palliative care or appropriate management. Clin Gastroenterol Hepatol 2014;12:692-8.

12 Glaser B SAL. Time for dying. Chicago, IL: Aldine Publishing, 1968: 1-288.

13 Lunney JR, Lynn J, Foley DJ, et al. Patterns of functional decline at the end of life. JAMA 2003;289:2387-92.

14 Murray SA, Kendall M, Boyd K, et al. Illness trajectories and palliative care. BMJ 2005;330:1007-11.

15 Teno JM, Weitzen S, Fennell ML, et al. Dying trajectory in the last year of life: does cancer trajectory fit other diseases? J Palliat Med 2001;4:457-64.

16 Addicott R. Delivering better end-of-life care in England: barriers to access for patients with a non-cancer diagnosis. Health Econ Policy Law 2012;7:441-54.

17 De Korte-Verhoef MC, Pasman HRW, Schweitzer BPM, et al. Reasons for hospitalisation at the end of life: differences between cancer and non-cancer patients. Support Care Cancer 2014;22:645-52.

18 Murray SA, Sheikh A. Palliative care beyond cancer: care for all at the end of life. BMJ 2008;336:958-9.

19 Murtagh FEM, Preston M, Higginson I. Patterns of dying: palliative care for non-malignant disease. Clin Med 2004;4:39-44.

20 Bostwick D, Wolf S, Samsa G, et al. Comparing the palliative care needs of those with cancer to those with common non-cancer serious illness. J Pain Symptom Manage 2017;53:1079-84.

21 Hess S, Stiel S, Hofmann S, et al. Trends in specialized palliative care for non-cancer patients in Germany--data from the national hospice and palliative care evaluation (HOPE). Eur J Intern Med 2014;25:187-92.

22 Goodridge D, Lawson J, Duggleby W, et al. Health care utilization of patients with chronic obstructive pulmonary disease and lung cancer in the last 12 months of life. Respir Med 2008;102:885-91.

23 Gore JM, Brophy CJ, Greenstone MA. How well do we care for patients with end stage chronic obstructive pulmonary disease (COPD)? A comparison of palliative care and quality of life in COPD and lung cancer. Thorax 2000;55:1000-6.

24 Claessens MT, Lynn J, Zhong Z, et al. Dying with lung cancer or chronic obstructive pulmonary disease: insights from support. study to understand prognoses and preferences for outcomes and risks of treatments. J Am Geriatr Soc 2000;48:S146-53.

25 Edmonds $\mathrm{P}$, Karlsen S, Khan S, et al. A comparison of the palliative care needs of patients dying from chronic respiratory diseases and lung cancer. Palliat Med 2001;15:287-95.

26 Skilbeck J, Mott L, Page H, et al. Palliative care in chronic obstructive airways disease: a needs assessment. Palliat Med 1998;12:245-54.

27 Tranmer JE, Heyland D, Dudgeon D, et al. Measuring the symptom experience of seriously ill cancer and noncancer hospitalized patients near the end of life with the Memorial symptom assessment scale. J Pain Symptom Manage 2003;25:420-9.

28 Fan VS, Curtis JR, Tu S-P, et al. Using quality of life to predict hospitalization and mortality in patients with obstructive lung diseases. Chest 2002;122:429-36.

29 McKinley RK, Stokes T, Exley C, et al. Care of people dying with malignant and cardiorespiratory disease in general practice. $\mathrm{Br} J$ Gen Pract 2004;54:909-13.

30 Au DH, Udris EM, Fihn SD, et al. Differences in health care utilization at the end of life among patients with chronic obstructive pulmonary disease and patients with lung cancer. Arch Intern Med 2006;166:326-31.

31 Harrison N, Cavers D, Campbell C, et al. Are UK primary care teams formally identifying patients for palliative care before they die? $\mathrm{Br} \mathrm{J}$ Gen Pract 2012;62:e344-52.

32 Pedersen CB. The Danish civil registration system. Scand J Public Health 2011;39:22-5.

33 Schmidt M, Pedersen L, Sørensen HT. The Danish civil registration system as a tool in epidemiology. Eur J Epidemiol 2014;29:541-9.

34 Danish National Register of Causes of D. Year report 2012, 2012. 
35 Helweg-Larsen K. The Danish register of causes of death. Scand J Public Health 2011;39:26-9.

36 Schmidt M, Schmidt SAJ, Sandegaard JL, et al. The Danish national patient registry: a review of content, data quality, and research potential. Clin Epidemiol 2015;7:449-90.

37 Charlson ME, Pompei P, Ales KL, et al. A new method of classifying prognostic comorbidity in longitudinal studies: development and validation. J Chronic Dis 1987;40:373-83.

38 Thygesen SK, Christiansen CF, Christensen S, et al. The predictive value of ICD-10 diagnostic coding used to assess Charlson comorbidity index conditions in the population-based Danish national Registry of patients. BMC Med Res Methodol 2011;11:832288-11-83.

39 De Roo ML, Block LV, Donker GA. Hospitalizations of cancer patients in the last month of life: quality indicator scores reveal large variation between four European countries in a mortality follow-back study 2014. BMC Palliative Care:13.

40 Abarshi EA, Echteld MA, Van den Block L, et al. Recognising patients who will die in the near future: a nationwide study via the Dutch sentinel network of GPs. Br J Gen Pract 2011;61:e371-8.

41 Moens K, Higginson IJ, Harding R, et al. Are there differences in the prevalence of palliative care-related problems in people living with advanced cancer and eight non-cancer conditions? A systematic review. J Pain Symptom Manage 2014;48:660-77.

42 Teno JM, Gozalo PL, Bynum JPW, et al. Change in end-of-life care for Medicare beneficiaries: site of death, place of care, and health care transitions in 2000, 2005, and 2009. JAMA 2013;309:470-7.

43 Wachterman MW, Pilver C, Smith D, et al. Quality of end-of-life care provided to patients with different serious illnesses. JAMA Intern Med 2016;176:1095-102.

44 Lastrucci V, D'Arienzo S, Collini F, et al. Diagnosis-Related differences in the quality of end-of-life care: a comparison between cancer and non-cancer patients. PLoS One 2018;13:e0204458.

45 Ostgathe C, Alt-Epping B, Golla H, et al. Non-Cancer patients in specialized palliative care in Germany: what are the problems? Palliat Med 2011;25:148-52.
46 Bekelman DB, Rumsfeld JS, Havranek EP, et al. Symptom burden, depression, and spiritual well-being: a comparison of heart failure and advanced cancer patients. J Gen Intern Med 2009;24:592-8.

47 Wiskar K, Celi LA, Walley KR, et al. Inpatient palliative care referral and 9-month Hospital readmission in patients with congestive heart failure: a linked nationwide analysis. J Intern Med 2017;282:445-51.

48 Spilsbury K, Rosenwax L, Arendts G, et al. The impact of community-based palliative care on acute hospital use in the last year of life is modified by time to death, age and underlying cause of death. A population-based retrospective cohort study. PLoS One 2017;12:e0185275

49 Brumley RD, Enguidanos S, Cherin DA. Effectiveness of a homebased palliative care program for end-of-life. J Palliat Med 2003;6:715-24

50 Brian Cassel J, Kerr KM, McClish DK, et al. Effect of a home-based palliative care program on healthcare use and costs. J Am Geriatr Soc 2016;64:2288-95.

51 Riolfi M, Buja A, Zanardo C, et al. Effectiveness of palliative homecare services in reducing hospital admissions and determinants of hospitalization for terminally ill patients followed up by a palliative home-care team: a retrospective cohort study. Palliat Med 2014;28:403-11.

52 McNamara BA, Rosenwax LK, Murray K, et al. Early admission to community-based palliative care reduces use of emergency departments in the ninety days before death. $J$ Palliat Med 2013:16:774-9.

53 Spilsbury K, Rosenwax L, Arendts G, et al. The association of community-based palliative care with reduced emergency department visits in the last year of life varies by patient factors. Ann Emerg Med 2017;69:416-25.

54 Lyngaa T, Christiansen CF, Nielsen $\mathrm{H}$, et al. Intensive care at the end of life in patients dying due to non-cancer chronic diseases versus cancer: a nationwide study in Denmark. Crit Care 2015;19:413.

55 Statistics D. Out-Patient treatments. Denmark: News from Statistics, 2013.

56 Andersen M, Hansen MB, Grønvold M. Dansk Palliativ database Årsrapport 2016. Dansk Multidisciplinær cancer Gruppe for Palliativ Indsats, 2016. 